
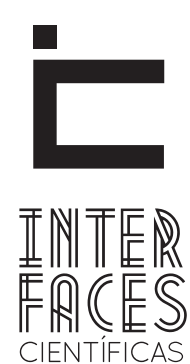

EDUCAÇÃO

ISSN IMPRESSO 2316-333X

ISSN ELETRÔNICO 2316-3828

DOI 10.17564/2316-3828.2015v3n3p97-107

\title{
AS POLÍTICAS EDUCACIONAIS E O PAPEL DO GESTOR NO CURSO DE BACHARELADO DE ADMINISTRAÇÃO
}

Sandra de Lourdes Gonçalves ${ }^{1}$

\section{RESUMO}

0 artigo foi realizado no Estado de Alagoas, com a escolha de Maceió como localização para a realização de um estudo de caso, por ter a maior concentração de cursos de Administração do Estado. Desta forma, foi escolhida uma Instituição de Ensino Superior (IES) privada do Estado, cujo nome não foi autorizado a divulgação. A análise das pesquisas e do referencial teórico leva ao entendimento que a expansão do ensino superior reforça a diretriz de certificar a mão de obra especializada para exercer tarefas complexas no mercado de trabalho. Esse tipo de certificação de mão de obra tende a formar cidadãos aptos a realizar tarefas complexas no mercado e de ocupar cargos de gerência na produção, mas que dificilmente formará um cidadão capaz de controlar quem o dirige.

\section{PALAVRAS-CHAVE}

Ensino Superior Privado. Mercado de Trabalho. Empresariamento do Ensino Superior. 


\section{ABSTRACT}

The article was conducted in the State of Alagoas, Maceió with the choice as location for conducting a case study, for having the highest concentration of courses in the State Administration. Thus, we have chosen a private Higher Education Institution (HEI) of the State, whose name has not consented to the release. The analysis of the research and the theoretical framework leads to the understanding that the expansion of higher education strengthens the guideline to certify skilled labor to perform complex tasks in the

\section{RESUMEN}

El artículo se llevó se cabo en el estado de alagoas, maceió con la elección como lugar para la realización de un estudio de caso, por tener la mayor concentración de cursos en la administración del estado.Por lo tanto, hemos optado por una institución privada de educación superior (ies) del estado, cuyo nombre no ha dado su consentimiento para la liberación. El análisis de la investigación y el marco teórico lleva a la comprensión de que la expansión de la educación superior fortalece la pauta para certificar mano de obra calificada para llevar a cabo tareas complejas en el mercado de job market. This type of certification of labor tends to form able to perform complex tasks in the market and citizens to occupy management positions in production, but that hardly made a citizen able to control who directs.

\section{KEYWORDS}

Private Higher Education. Labor market. Entrepreneurship in Higher Education. Education.

trabajo. Este tipo de certificación de la mano de obra tiende a formar capaz de realizar tareas complejas en el mercado y los ciudadanos para ocupar puestos de responsabilidad en la producción, pero eso no hizo un ciudadano capaz de controlar que dirige.

\section{PALABRAS CLAVE}

Educación Superior Privada. Mercado de Trabajo. El Espíritu Empresarial en la Educación Superior. Educacion. 


\section{INTRODUÇ̃̃̃O}

A base do artigo foi realizada no Estado de Alagoas, localizado na região Nordeste do Brasil. Dividido em 102 municípios. Conforme contagem populacional realizada pelo Instituto Brasileiro de Geografia e Estatística (IBGE, 2010), a população alagoana totaliza 3.120.494 habitantes. Apresenta crescimento demográfico de $1 \%$ ao ano e a densidade demográfica é de 112,3 habitantes por quilômetro quadrado. A maioria dos habitantes reside em áreas urbanas (73,6\%) e a população rural corresponde a $26,4 \%$. A expectativa de vida do alagoano é de 66 anos. Maceió, capital de Alagoas, é a cidade mais populosa do estado, possui 932.748 habitantes.

A ausência de políticas públicas eficazes faz com que Alagoas apresente vários problemas socioeconômicos. O estado possui o menor Índice de Desenvolvimento Humano (IDH) do Brasil, com média de 0,677. A taxa de analfabetismo, também, é a maior do país: analfabetismo, 24,6\%; analfabetismo funcional, $36,5 \%$.

Este artigo foi realizado por meio de estudo de caso, que segundo Severino (2007, p. 121) “é a pesquisa que se concentra no estudo de um caso particular, considerado representativo de um conjunto de casos análogos", ou seja, quando envolve o estudo profundo e exaustivo de um ou poucos objetos de maneira que se permita o seu amplo e detalhado conhecimento.

A escolha de Maceió como localização para a realização de um estudo de caso se deu pelo fato de ser este Município o de maior concentração de cursos de Administração do Estado. Desta forma, foi escolhida uma Instituição de Ensino Superior (IES) privada, relacionada na lista do Instituto Nacional de Estudos e Pesquisas Educacionais Anísio Teixeira (INEP)/Ministério da Educação (MEC), do ano de 2009, no ranking das cinco melhores IES Privadas do Estado. A divulgação do nome não foi autorizada. Seu quadro de docente para o Curso de Administração conta com um total de dezenove, cuja formação acadêmica perpassa pelas áreas de ciências contábeis, economia, matemática, psicologia, entre outros.

Foi utilizada, no estudo de caso, a abordagem de pesquisa qualiquantitativa, onde se considera que há uma relação dinâmica entre o mundo real e o sujeito, isto é, um vínculo indissociável entre o mundo objetivo e a subjetividade do sujeito que não pode ser traduzido em números.

Quanto à formação, o quadro de docente do curso é composto de dez mestres, dois doutores e sete especialistas, dos quais sete trabalham em jornada de tempo integral dentro da instituição, com base no que está disposto no art. 69, do Decreto n 5.773/06, com quatro docentes em tempo parcial e oito horistas, possuindo os seguintes percentuais de titulações $11 \%$ de doutores, $52 \%$ mestres e $37 \%$ especialistas.

A IES trabalha a qualificação do seu quadro de docentes, colocando à disposição, semestralmente, uma Jornada Pedagógica, com intuito de trabalhar formas de atuação e qualificação do quadro. Segundo Leher (1999), “a empresa precisa utilizar de maneira eficiente o cérebro de seus funcionários que, por isso, devem ser depositários de conhecimento útil para o capital”. Assim, os docentes dessa IES poderão conciliar o conhecimento adquirido com suas atividades de docência e sua prática profissional.

\section{AS POLÍTICAS EDUCACIONAIS E O PAPEL DO GESTOR NO CURSO DE BACHARELADO DE ADMINISTRAÇ̃̃O}

0 artigo teve como base a análise documental do Projeto Pedagógico do Curso (PPC), foi realizada por meio da literatura consultada e pelo material apresentado pela IES estudada, que propôs analisar a estrutura curricular do curso Bacharelado em Administração, que em seus eixos Estruturantes e o Eixo de Temas Transversais, estão em conformidade com as Diretrizes do CNE, conforme o art. 5 , do DCCG (2008). 
Com base nas Diretrizes Curriculares para os Cursos de Graduação (2008), no que dizem respeito ao curso Bacharelado de Administração, os eixos estruturantes sistematizam a complementaridade dos conteúdos, saberes, ações, e competências verticalmente, em grupos de unidades programáticas e/ou disciplinas que guardam certa proximidade quanto à finalidade específica da formação. Representam os eixos sobre os quais os conteúdos são aglutinados no sentido orgânico, obedecendo às diretrizes curriculares e resoluções do MEC. Podem-se citar como exemplos os seguintes eixos estruturantes trabalhados em outros quatro eixos: 1. Eixo de Fenômenos e Processos Básicos; 2. Eixo de Práticas Investigativas; 3. Eixo de Formação específica; 4. Eixo de Práticas Profissionais.

Já os Temas Transversais são referentes aos temas ou assuntos que ultrapassam a abrangência dos conteúdos programáticos formalmente constituídos, abordando questões de ordem ética, política e pedagógica que transpassam as ações universitárias. Por meio da transversalidade são abordadas as questões de interesse comum da coletividade e independente da área de conhecimento. Podem-se citar temas como ecologia, formação humanista e cidadã, desenvolvimento sustentável, preservação cultural e diversidade, inclusão social, metas individuais versus metas coletivas, competitividade versus solidariedade, empreendedorismo, ética corporativista versus ética centrada na pessoa etc., todos comprometidos com a missão institucional, com a educação como um todo e com o Projeto Pedagógico Institucional.

Segundo o Gestor Acadêmico da Instituição Mantenedora, o curso está estruturado de acordo com o novo cenário globalizado. Sua criação teve como suporte a nova realidade do ensino da administração, suas perspectivas mercadológicas, e motivadas também pelo novo perfil de "homem-profissional-cidadão" que segundo a gestão acadêmica da Instituição, é "o que se pretende formar".

Segundo palavras do Gestor Acadêmico da Instituição Mantenedora (ANO),
Essa formação exige um currículo não apenas limitado ao ensino das técnicas de escrituração e de demonstrações contábeis e financeiras, mas direcionado para o desenvolvimento da pesquisa, da consciência critica, da liderança e da tecnologia, tornando-se um curso cada vez mais voltado para os aspectos de gerenciamento dos negócios, desenvolvendo no discente capacidade de análise necessária para interpretar os fatos econômicos.

Desta forma, e conforme o que afirma Paes de Paula e Rodrigues (2006), no campo da Administração existe uma crescente tendência para reprodução de perspectivas menos voltadas para uma vertente critica na gestão e mais voltadas para uma vertente relacionada ao mainstream ${ }^{2}$. Essa tendência reflete-se no exagero na instrumentalização dos alunos, que são condicionados a dar respostas padronizadas às empresas, estando pouco abertos a uma reflexão mais crítica e à busca de soluções próprias. Nesse sentido, um curso cujo currículo considere vertentes associadas às ciências sociais e humanas, ao invés de ser voltado apenas para o ensino de técnicas administrativas, torna-se o cenário onde se inserem as maiores possibilidades e potencialidades para o desenvolvimento dos diversos campos pertencentes aos Estudos Críticos em Administração.

A análise da estrutura curricular da IES em estudo remete a Leher (1999), ao esclarecer que a partir da década de 1990, o Banco Mundial (BM) dedicou-se cada vez mais em adequar as instituições de ensino superior à era do mercado.

Sendo assim, o ponto de vista colocado pelo Gestor Acadêmico está de acordo com o estudo elaborado pelo Banco Mundial (2008), que analisou os problemas e deficiências derivadas do processo de preparação do Brasil para enfrentar os desafios da economia do conhecimento, os quais repercutem no processo de inovação nas empresas e afeta negativamente a competitividade do País.

2. 0 termo "mainstream" refere-se a uma corrente principal, uma corrente de pensamentos e ícones culturais reconhecido pela maioria da população. Uma mídia ou cultura de massa pode ser incluída nesse aspecto. 
Com Base na fala do Gestor Acadêmico, o setor privado busca encontrar formas de atuação cada vez mais diretas na definição das políticas educacionais, reivindicando uma maior participação junto aos órgãos públicos, comissões e conselhos, por uma maior autonomia e não interferência dessas mesmas instâncias na gestão das IES Privadas.

Concomitantemente, revela que a IES atua junto à sociedade civil, na tentativa de angariar uma imagem positiva de seu sistema de educação superior, apresentando-o como mais democrático, mais adequado às necessidades do mercado e capaz de acompanhar as transformações da sociedade global.

Com base na fala do gestor e do que foi esclarecido por Leher (1999), podem-se levar em consideração as mudanças ocorridas a partir da década de 1990. As faculdades, centros universitários e universidades particulares desfrutavam do benefício da superação da demanda em relação à oferta, permitindo desta forma, conforme visto nas informações extraídas dos relatórios do MEC/INEP, que a tendência de surgimento de IES privadas fosse crescente, desde que atendessem exigências do MEC (BRASIL, 2009), bem como na intenção de que a educação superior forme para o trabalho complexo.

Com base nas entrevistas realizadas com o coordenador e Gestor Acadêmico e, segundo Vale (2008), à educação superior cabe formar para o trabalho complexo, se o faz dentro dos marcos de subordinação que marcam a inserção brasileira na divisão internacional do trabalho: a adaptação, cópia e montagem da tecnologia e formatação das mentalidades a uma cultura empresarial.

O Coordenador (ANO) da IES em estudo esclarece que em seu entendimento, "o professor deve ter condições de capacitar o aluno na profissão escolhida, reafirmando seu papel, ou seja, das IES, que seria então de formar o indivíduo como força de trabalho para o mercado". Dessa forma, o indivíduo deverá ser trabalhado nas IES para reproduzir as condições de vida sob o capital, o que vem se estabelecendo no Brasil de FHC a Lula da Silva, conforme visto anteriormente.

Segundo Silva Jr. e Sguissardi (2000), a maior preocupação é a ampliação das vagas em cursos que possibilitem retorno financeiro maior, como pode ser visto nos cursos de Direito, Administração, Contabilidade, Processamento de Dados, entre outros, o que vem gerando na concorrência, um canibalismo; a prática de canibalismo nas empresas ocorre quando a venda de um dos produtos de uma empresa reduz as vendas de outros dela mesma.

Portanto, o censo de 2009 comprova essas informações, conforme os dados retirados do relatório INEP/MEC 2009: as matrículas da educação superior nas redes pública e privada, quase em sua totalidade, concentram-se nos cursos de Administração (1,1 milhão), Direito (651 mil), Pedagogia (573 mil) e Engenharia (420 mil). Na educação à distância, os dois cursos mais escolhidos são Pedagogia e Administração, que detêm $61,5 \%$ do total de matrículas. 0 curso de administração teve uma variação em 2005-2009 de 51\%, em 2009 chegando a ter 1.102 .579 matrículas.

O Censo INEP/MEC (2010) classifica os cursos em áreas. Dos 1.553 nomes de cursos diferentes existentes, 352 áreas são de interesse da Organização para a Cooperação e Desenvolvimento Econômico (OCDE), órgão internacional e intergovernamental, cuja sede está localizada em Paris, França, e que reúne os trinta e quatro países mais industrializados e também alguns emergentes, para trocar informações e alinhar políticas, com o objetivo de potencializar seu crescimento econômico e colaborar com o desenvolvimento de todos os demais países membros.

As áreas de maior interesse da OCDE são as de cursos que podem ajudar no desenvolvimento econômico e pedagógico e que detêm $62.5 \%$ das matrículas, sendo elas nas áreas de ciências sociais, negócios, direito e educação. 
A nova competição com a adoção de práticas estratégicas deliberadas e de maior consistência para a melhoria da vantagem competitiva da empresa exige novas estratégias, representadas por práticas mais agressivas, inovadoras e futuristas que influenciem a área de atuação. Portanto, essas mudanças previstas para a educação superior, via Lei de Diretrizes e Bases da Educação (LBD, 1996), no que tange aos seus artigos $7^{\circ}$ e $43^{\circ}$, repõem para os dirigentes das IES Privadas o dilema da submissão às normas legais e às tentadoras possibilidades oferecidas pelo mercado, cujos atrativos atuais são muito fortes, diante da estruturação produtiva e das mudanças macro e microeconômicas em curso no país.

As IES privadas almejam autonomia, para que possa planejar sua participação em um mercado extremamente competitivo, principalmente por estarem inseridas no setor de serviços, setor este que segundo IBGE (2010), se mostra em franca expansão, encontrando no Estado um de seus entraves, diante da reestruturação produtiva e econômica. Por outro lado, as Instituições Mantenedoras detêm o poder e a autonomia dessas instituições. Em alguns casos possuem reitores funcionários, onde mesmo assim tendem a seguir as regras dos donos e/ou mantenedores.

Uma tendência encontrada nas IES privadas é a de manter um gestor acadêmico para assegurar que a política acadêmica seja planejada a partir das orientações emanadas das estratégias da mantenedora. Para que as IES privadas possam atender às necessidades sociais não cobertas pelo Estado, evidencia-se uma vontade de somente serem subjugadas aos ditames da sociedade civil e do mercado, sem controle do Estado, podendo desta forma, alcançar seu objetivo principal: o lucro financeiro e o aumento e estabilidade patrimonial. Segundo Lima (2002), as orientações contidas no documento de 1994, do Banco Mundial, são extremamente importantes para se passar regras de gestão a serem adotadas pelas instituições superiores privadas:
Portanto, as IES privadas possuem uma gestão orientada para a produção empresarial. Deste modo, em muitos casos deixam de ter a produção acadêmico-científica como objetivo específico devido seu alto custo, sendo identificada pelos gestores, como uma das maiores dificuldades encontradas. Nesse sentido, o ensino predominantemente no setor privado, conforme esclarece Silva Jr. e Sguissardi (2000) tem necessidade de ser reconfigurado:

\section{[...] as instituições privadas estão sendo forçadas legal e economicamente a se reconfigurarem, a fim de ga- rantirem o espaço institucional que até então ocupa- vam no mercado, o que tem conduzido seus gestores e suas entidades e associações representativas a duas direções: 1) buscar minimizar a ação do Estado; e 2) promover mudanças conforme a conjuntura política e econômica. (SGUISSARDI \& SILVA JR., 2000, p. 167).}

O processo de reorganização do ensino superior provoca mudanças institucionais que afetam suas atividades e estruturas, adquirindo outras dimensões, e, seus proclamados fins, deixando transparecer a outra face da mercantilização que é a referência identitária para as instituições, sua forma capitalista. Silva Jr. \& Sguissardi (2000) esclarecem que há necessidade por parte das IES privadas, de uma aproximação com o setor produtivo, no sentido do que deve ser "produzido".

Baseado na questão da subsunção institucional ao processo produtivo, colocado por Silva Jr. \& Sguissardi (2000), o Coordenador da IES estudada, quando perguntado sobre sua atuação na coordenação do ensino superior, respondeu que pode ser considerada como "muito boa, pois consegue agregar conhecimentos técnicos com os de docência" (Grifo do autor), mostrando claramente a necessidade de aproximação da IES com o setor produtivo. Neves (2004) mostra claramente a responsabilidade que a iniciativa privada tem, em relação à formação técnica e ético-política do trabalho qualificado, que está a cargo da educação superior.

No que concerne à questão da subsunção da IES ao mercado de trabalho, principalmente no que diz 
respeito ao currículo, na visão do coordenador entrevistado (2011), se coloca da seguinte forma: "Sem dúvida, pois o mercado é que vai dar visibilidade a IES, pois se os egressos tiverem boa participação no mercado de trabalho o retorno é imediato e positivo".

Desta forma, quando questionado sobre a percepção que possui acerca do papel do coordenador de uma IES privada, o coordenador informou que seu papel "É adequar o Projeto Pedagógico do Curso (PPC) às realidades regional e nacional e quem sabe até internacional, articulando com o mercado, sempre". Para efeito de esclarecimento, disse ainda: "0 Coordenador tem que ter um profundo e atualizado conhecimento de seu curso, do perfil do profissional que está formando e do mercado em que este profissional irá atuar”. Quanto à questão da subsunção da IES ao mercado de trabalho, o mesmo esclarece que essa subsunção age diretamente na forma de trabatho dos coordenadores.

Neves (2004) esclarece que o papel das reformas no ensino superior e o papel da escola, fazem parte de uma estratégia estatal. Assim, vê-se claramente em que os coordenadores entendem seu papel nesse processo de formação de um novo intelectual urbano, preparado para atender os anseios da produção, sendo eles mesmos parte desse processo, preparados para cada vez mais tornar a faculdade mais competitiva e assim, serem mais procuradas para esse fim (NEVES, 2004).

Quando questionados como a IES prepara seu quadro docente para atender a exigência de mercado, como seria o papel de coordenador e o de professor em relação às exigências do mercado de trabalho, o coordenador afirmou que o papel (dele e da Instituição) "é estar atendo às exigências do mercado quanto às necessidades do desenvolvimento de competências e habilidades desses novos profissionais".

Portanto, pode-se atentar que mesmo não tendo consciência disso, o coordenador trabalha os meca- nismos de consenso que buscam combinar formas de autodisciplina, com persuasão e consenso, assim como colocado por Gramsci (2001), em que afirma que a meta é a necessidade da indústria moderna de generalizar o "novo tipo humano".

Carvalho (2006) esclarece que a expansão de matrículas, cursos e instituições no setor privado resultou na criação de um número excessivo de vagas, embora a demanda potencial por ensino superior não se restrinja ao número de concluintes do ensino médio, mas diz respeito, também, àqueles que retornam tardiamente aos bancos escolares. Tal colocação apresenta indícios de que o segmento privado disponibiliza um contingente de vagas não procuradas pelos estudantes.

Segundo Gramsci (2001), o Estado é investido de uma função de primeiro plano no sistema capitalista, como empresa (holding estatal) que concentra a poupança a ser posta à disposição da indústria e da atividade privada e como investidor a médio e longo prazo. O que torna a função do Estado atualíssima, e ainda com base em Gramsci, o Estado é interventor para controlar se os investimentos realizados por seu intermédio estão sendo bem administrados e, desse modo, compreende-se pelo menos um aspecto das discussões teóricas sobre o regime corporativo. Mas o simples controle não é suficiente. Com efeito, não se trata apenas de conservar o aparelho produtivo tal como este exista num determinado momento; trata-se de reorganizá-lo, a fim de desenvolvê-lo paralelamente ao aumento da população e das necessidades coletivas.

A nova competição entre as IES, com a adoção de práticas estratégicas deliberadas e de maior consistência para a melhoria da vantagem competitiva da empresa exige novas formas de atuar, representada por práticas mais agressivas, inovadoras e futuristas, que influenciem a área de atuação. Portanto, essas mudanças previstas para a educação superior, como a utilização dos índices de qualidade, visam repor, para os dirigentes das IES privadas, o dilema da submissão às normas legais e as possibilidades oferecidas pelo 
mercado, de absorção de mão de obra produtiva, cujos atrativos atuais são muito fortes diante da estruturação produtiva e das mudanças macro e microeconômicas em curso no país.

\section{O Coordenador (ANO) afirma também que:}

As exigências são do mercado de trabalho pelo grau de conhecimento necessário para o exercício qualificado. Sendo hoje fundamental que as pessoas não parem no tempo. 0 aprendizado na graduação representa apenas uma condição inicial para ingressar no mercado de trabalho. Para manter-se nele é preciso se atualizar sempre e buscar formas de aprofundar o conhecimento.

A forma como o docente é preparado, leva em conta a necessidade das IES privadas para fazer cumprir a exigência de mercado. Em relação a isto, o Coordenador da IES em estudo afirmou que o papel do Coordenador é atender as exigências do mercado, quanto ao desenvolvimento das competências e habilidades desses novos profissionais.

Constata-se nas entrevistas, que a IES estudada está ciente da necessidade do favorecimento da formação contínua ou em serviço do seu corpo docente, mediante cursos, seminários, pós-graduação (lato e stricto sensu), que serão implantados, podendo, dessa forma, segundo palavras do Gestor Acadêmico, favorecer as iniciativas de formação dos professores, investindo ainda para que a Instituição possa atender as exigências do MEC. Pimenta (2010), sobre essas formações afirma que constituem regra geral, pois há certo consenso de que a docência no ensino superior não requer formação no campo do ensinar.

Nas entrevistas evidencia-se, não só pela coordenação, mas também pelo discurso do gestor acadêmico da mantenedora, que o mais importante é preparar o corpo discente para que enfrente o mercado competitivo, já que os intelectuais urbanos em sentido estrito são cada vez mais formados nas escolas de nível superior, com sua formação direcionada para a produção científica e tecnológica do conhecimento necessário à reprodução ampliada do capital, como colocado por Neves (2004, p. 7), sendo o curso de Administração um dos cursos mais concorrido.

Em relação ao crescimento do número das matrículas nos cursos de Direito e Administração nos cursos presenciais, e de Administração e Pedagogia nos cursos de EAD, no Brasil, conforme informações do INEP/MEC, o Coordenador pontuou que a busca pelo curso de Administração é pela crescente posição econômica e pela necessidade cada vez maior das empresas terem em seus quadros profissionais com competência e habilidade na administração, numa perspectiva holística. Para ele, esse cenário fica mais evidente no eixo Sul-Sudeste.

Para o Coordenador (ANO), o ensino superior brasileiro é desbalanceado, em parte em função das demandas por cursos. O Brasil forma por ano cerca de 110 mil administradores, segundo o Censo (2009). Cerca de $20 \%$ dos profissionais formados anualmente no país. Número muito elevado para que todo este contingente possa ser satisfatoriamente qualificado e absorvido pelo mercado de trabalho.

Comprovando a forte tendência de subsunção institucional ao processo produtivo e econômico, o empresariamento da gestão é condicionado, o que revela cada vez mais os desenhos organizacionais das IES privadas como empresas do setor de serviços. Como em todo negócio, deve-se ter e reter profissionais que somem conhecimentos e habilidades para que consiga dar sustentabilidade aos propósitos da IES. Enfim, a gestão profissional é questão primordial para o crescimento e desenvolvimento de qualquer empreendimento que colocamos em prática. Só não podemos esquecer os diferenciais de cada segmento.

Desta forma, fica a IES privada com função de integrar o ensino ao setor produtivo pela capacitação da força de trabalho, ou seja, por meio da preparação do 
indivíduo para os processos produtivos e econômicos, em níveis distintos de complexidade. Segundo Neves (2004, p. 6), cabe à faculdade formar o intelectual de novo tipo, na sociedade urbano-industrial. "A escola é o instrumento para elaboração desses intelectuais de novo tipo em diversos níveis. [...] Além disso, Os intelectuais urbanos educam e são educados para a submissão" (NEVES, 2004, p. 6. Grifo do autor).

\section{CONSIDERACÕ̃ES REFLEXIVAS}

As considerações finais pretendem deixar claro que o objetivo do presente trabalho vislumbrou novas perspectivas de estudos, por considerar que as pesquisas realizadas mostram uma realidade mais complexa, que propiciarão novas necessidades de reflexão.

Diante da necessidade de desvelamento da estrutura funcional capitalista que se transforma em estímulo para o desenvolvimento intelectual dos trabalhadores, a luta organizada contra o capital deixa de ser apenas econômico-política.

A relação imposta pelas políticas educacionais vigentes se dá pela imensa pressão exercida, para que se cumpram as metas das empresas e indústrias, tornando isso um objetivo da formação educacional. Portanto, essas estratégias de coerção e consenso que são fundamentais, são produtos da adaptação do ser humano à produção e reprodução da base material, ou seja, servem para o desenvolvimento das condições econômicas de produção vigentes.

Cabe destacar que o governo Lula deu continuidade às políticas educacionais postas em marcha pelo governo anterior, desencadeadas pela reforma educacional da década de 1990. Nessa direção, a política educacional implantada pelo governo Lula atende aos pressupostos das orientações ditadas pela lógica de mercado imposta pelas relações econômicas neoliberais, com implicações diretas nos projetos educacionais executados nos estados brasileiros. Com efeito, compreende-se que o governo Lula adotou políticas regulares de educação, na perspectiva de recuperar o papel do Estado como promotor de políticas para o campo da educação, bem como tentar corrigir distorções naturais para um país do tamanho do Brasil e com consideráveis diferenças regionais.

O estímulo pelo Estado ao empresariamento da educação superior nas últimas décadas no Brasil se inclui entre essas novas estratégias econômicas do Estado capitalista, de reprodução ampliada do capital, tanto no que diz respeito ao fortalecimento de frações do bloco no poder quanto ao aumento da produtividade da força de trabalho pela ampliação da mais-valia e da exploração.

Ao analisar o fórum promovido pela Organização para a Cooperação e Desenvolvimento Econômico (OCDE), em 2002, salienta-se o fato de que a educação pode contribuir para a edificação de sociedades tolerantes, democráticas e prósperas, e afirma que a partir desse cenário é que as políticas educacionais são desenhadas, as reformas passam a ser internacionais.

Coloca, ainda, que as políticas educacionais têm seus objetivos determinados pelos organismos multilaterais, cujos fins estão voltados para o crescimento econômico e erradicação da pobreza, devendo, portanto, alinhar a escola à empresa e aos conteúdos ensinados, tendo em vista as exigências do mercado.

Nesse sentido, as considerações permitem retratar as contradições por compreender que há muito a ser descortinado acerca da problemática em estudo, ou seja, analisar como o docente de uma Instituição de Ensino Superior (IES) privada entende as políticas educacionais implantadas pelos últimos governos e como elas interferem no trabalho do docente.

Cabe à faculdade formar o intelectual de novo tipo nas sociedades urbano-industriais, pois essa faculdade é considerada como instrumento para capacitação desses intelectuais de novo tipo em diver- 
sos níveis. Esses intelectuais urbanos educam e são educados para a submissão.

Diante disso, a importante reflexão que se chega ao analisar este trabalho é que os coordenadores entendem seu papel nesse processo, que é o de formar um novo intelectual urbano, preparado para atender os anseios da produção, sendo eles mesmos parte desse processo.

Por fim, a análise das pesquisas e do referencial teórico leva a entender que a expansão do ensino superior reforça a diretriz de certificar a mão de obra especializada para exercer tarefas complexas no mercado de trabalho. Esse tipo de certificação de mão de obra tende a formar cidadãos aptos a realizar tarefas complexas no mercado e de ocupar cargos de gerência na produção, tanto no aparelho estatal, como na sociedade civil, mas dificilmente formará um cidadão capaz de pensar, de estudar, de criar e de controlar quem o dirige.

\section{REFERÊNCIAS}

BANCO Mundial. Conhecimento e inovação para a competitividade. Trad. Confederação Nacional da Indústria. Brasília: CNI, 2008.

BRASIL. Presidência da República. Casa Civil. Constituição da República Federativa do Brasil de 1988. Disponivel em: <http://www.planalto.gov.br/ccivil_03/constituicao/constitui\%C3\%A7ao.htm>. Acesso em: 5 set. 2009.

BRASIL. Instituto Brasileiro de Geografia e Estatística - IBGE. Disponível em: <http://www.ibge.gov.br/ home/estatistica/populacao/>. Acesso em: 5 set. 2010.

BRASIL. Ministério da Educação. Instituto Nacional de Estudos e Pesquisas Educacionais (INEP). Avaliação do Plano Nacional de Educação: Resumo Técnico: Censo da Educação Superior 2009. Brasília, DF: MEC/
INEP, 2010. Disponível em: <http//portal.mec.gov. br/>. Acesso em: 10 ago. 2011.

BRASIL. Ministério da Educação. Instituto Nacional de Estudos e Pesquisas Educacionais (INEP). Avaliação do Plano Nacional de Educação: Resumo Técnico: Censo da Educação Superior 2007. Brasília, DF: MEC/ INEP, 2010. Disponível em: <http//portal.mec.gov. br/>. Acesso em: 10 ago. 2011.

BRASIL. Ministério da Educação. Instituto Nacional de Estudos e Pesquisas Educacionais (INEP). Avaliação do Plano Nacional de Educação: Resumo Técnico: Censo da Educação Superior 2002. Brasília, DF: MEC/ Inep, 2010. Disponível no site: <http//portal.mec.gov. br/ >. Acesso em: 10.Ago.2011;

BRASIL. Lei de Diretrizes e Bases da Educação: Lei no 9.394 de 20 de dezembro de 1996, 3. Ed., Brasília: Senado Federal, Subsecretaria de Edições Técnicas, 2006;

CARNEIRO, Moacir Alves. LDB fácil: leitura crítico-compreensiva artigo a artigo. 16. Ed. Petrópolis, RJ: Vozes, 2009;

CARVALHO, Cristina Helena Almeida de. O PROUNI no governo Lula e o jogo político em torno do acesso ao ensino superior. Educ. Soc. [online], v.27, n.96, 2006. p.979-1000. ISSN 0101-7330.

FRAUCHES, C. C. (ORG.). Diretrizes Curriculares para os Cursos de Graduação. Brasília: ABMES, 2008.

GOVERnO DE ALAGOAS. Defesa Social de Alagoas. Disponível em: <http://www.defesasocial.al.gov.br/ plano-estadual-de-seguranca-publica/index_html/ diagnostico-da-seguranca-publica-em-alagoas $>$. Acesso em: 18 out. 2009.

GRAMSCI, A. Caderno 22 (1934): Americanismo e Fordismo. In: GRAMSCI, Antonio. Cadernos do Cárcere. V.4. Edição e tradução, Carlos Nelson Coutinho; coedição, Luiz Sérgio Henriques e Marco Aurélio Nogueira. Rio de Janeiro: Civilização Brasileira, 2001. p.241-282. 
LEHER, Roberto. Um novo senhor da educação? A política educacional do Banco Mundial para a periferia do capitalismo. Revista Outubro, n.3, 1999.

LEHER, Roberto. Educação no Governo de Lula da Silva: a Ruptura que não aconteceu. In: MAGALHÃES, J. P. A. et al. Os anos Lula: contribuições para um balanço crítico 2003-2010. Rio de Janeiro: Garamond, 2010.

LIMA, J. C. F.; NEVES, M. W. Fundamentos da educação escolar do Brasil contemporâneo. Rio de Janeiro: FIOCRUZ, 2006, p.241-287.

LIMA, K. R. S. Organizmos internacionais: O capital em busca de novos campos de exploração. in: NEVES, L. M. W. 0 empresariamento da educação: novos contornos do ensino superior no Brasil dos anos 1990. São Paulo: Xamã, 2002;

NEVES, L. M. W. Legislação e planejamento no processo de privatização da Educação superior in: NEVES, L. M. W. $O$ empresariamento da educação: novos contornos do ensino superior no Brasil dos anos 1990. São Paulo: Xamã, 2002.

NEVES, L. M. W. As reformas da educação superior e a formação de um intelectual urbano tipo. SIQUEIRA, A. C. de et al. (Orgs.). Educação Superior: uma reforma em processo. São Paulo: Xamã, 2006a. p.81-106;
NEVES, L. M. W.; LIMA, J. C. F. (orgs.). Fundamentos da Educação escolar do Brasil contemporâneo. Rio de Janeiro: FIOCRUZ/EPSJV, 2006b.

PIMENTA, S. G.; ANASTASIOU, L. G. C. Docência no Ensino Superior. 4.ed. São Paulo: Cortez, 2010. Coleção Docência em Formação;

SEVERINO, A, J. Metodologia do Trabalho Científico. 23.ed. São Paulo: Cortez, 2007.

SGUISSARDI, V. (Org.). Educação Superior: velhos e novos desafios, São Paulo: Xamã, 2000.

SGUISSARDI, V. Diferenciação e Diversificação: Marcas das Políticas de Educação Superior no final do século. In: SGUISSARDI, V. (Org.). Educação Superior: Velhos e novos desafios, São Paulo: Xamã, 2000.

SILVA JR, J. R.. Reforma do Estado e Educação no Brasil. São Paulo: Xamã, 2002. In: SOARES, A. A. R.. As Mudanças na Educação Brasileira no Contexto Neoliberal e suas Implicações no Ensino Superior. Texto apresentado no VIII Congresso Latino americano de Humanidades, 2007, Campos de Goytacazes

VALE, A. A. Considerações sobre a organização das IES privadas brasileiras: uma análise das propostas da ABMES - uma entidade representativa do setor privatista para o quadriênio 2007-2011. Revista Trabalho Necessário, v.6, n.7, 2008.

Recebido em: 16 de julho de 2014 Avaliado em: 02 de março 2015

Aceito em: 20 de março 2015 
1. Mestre em Educação Brasileira, pelo Programa de Pós-Graduação em Educação, do Centro de Educação - PPGE/CEDU, da Universidade Federal de Alagoas - UFAL, na Linha de Pesquisa de História e Política da Educação, no

Recebido em: 16 de Julho de 2014

Avaliado em: 2 de Março 2015

Aceito em: 20 de Março 2015
Grupo Trabalho: Estado, Sociedade e Educação. Graduada em Administração de Empresas, com habilitação em MARKETING pela Escola Superior ee Administração, Marketing e Publicidade - ESAMC / AL (2005), Especializada em Gestão Empresarial (2007) e Gestão de Projetos (2008), pela Escola Superior de Administração, Marketing e Publicidade - ESAMC.

E-mail: sandra.Igoncalves@yahoo.com 